\title{
Is the Ratio of Retracted Iranian Papers Compatible With Their Research Growth Rate? An International Database Survey
}

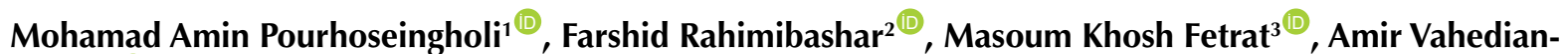 \\ Azimi $^{4 * \mathbb{C}}$ \\ ${ }^{1}$ Gastroenterology and Liver Diseases Research Center, Research Institute for Gastroenterology and Liver Diseases, \\ Shahid Beheshti University of Medical Sciences, Tehran, Iran \\ ${ }^{2}$ Department of Anesthesiology and Critical Care, School of Medicine, Hamadan University of Medical Sciences, \\ Hamadan, Iran \\ ${ }^{3}$ Department of Anesthesiology and Critical Care, Khatamolanbia Hospital, Zahedan University of Medical Sciences, \\ Zahedan, Iran \\ ${ }^{4}$ Trauma Research Center, Nursing Faculty, Baqiyatallah University of Medical Sciences, Tehran, Iran
}

*Corresponding Author: Amir Vahedian-Azimi, Ph.D., Associate Professor, Trauma Research Center, Nursing Faculty, Baqiyatallah University of Medical Sciences, Tehran, Iran. Tel: +98-09196017138, Fax: +98-021-87555487, Email: Amirvahedian63@gmail.com

Received December 20, 2020; Accepted February 7, 2021; Online Published March 7, 2021

\begin{abstract}
Background: Retraction of articles occurs as a result of scientific misconducts or honest errors.

Objectives: This study aimed to identify the frequency of retracted Iranian publications, compared to those of other countries and adjust them with influential parameters.

Methods: All publications that were indexed on the Scopus database from 2008 to 2017 and then retracted, due to scientific misconduct were extracted through the Retraction Watch database and selected as the research community. To calculate the growth of retraction for each proposed country (or region), first, the rate of an absolute number of retracted papers for the years 2013-2017 was divided by the similar number for years 2008-2012, then this rate was adjusted to the retracted rate which is similarly computed for the total retracted statistics of the world.

Results: Overall, 545 Iranian retracted publications from 2008 to 2017 were identified, of which 240 and 305 retracted articles were related to the first five years and the second five years of the study, respectively. The results showed that less than $1 \%(0.82)$ of all scientific articles published by Iranian researchers were retracted. However, the rate of retracted scientific articles in Iran compared to this rate in the world was significantly higher.

Conclusion: Although retracted Iranian publications make up a small percentage of all Iranian publications, the number of retracted publications is increasing. It is important to recognize the reasons for scientific misconducts and to provide researchers with proper education.
\end{abstract}

Keywords: Retracted Publication, Scientific Misconduct, Academic Integrity, Iran

\section{Background}

If it is determined that the published studies have significant defects, these studies should be retracted in order to avoid misleading potential readers. ${ }^{1}$ Retraction is a mechanism for the correction of literature and a warning to readers in relation to publications containing such serious defects or incorrect data. Unreliable data can be the result of an honest error or research misconduct. ${ }^{2}$ Evidence shows that there are several reasons for retracting publications, the most important of which are research misconduct, data fabrication, ethical misconduct, plagiarism, data falsification, multiple submissions and duplicate publications, copyright infringement, and ethical research ethics. ${ }^{3-6}$

The number and frequency of retraction publications are important indicators of the health of the scientific enterprise. Therefore, the study of retracted publications can provide valuable information about the status of adherence to ethical principles in scientific work. ${ }^{7} \mathrm{~A}$ considerable amount of literature has been published on retracted articles; some of these studies focus on general medicine, ${ }^{8,9}$ or specific subject areas, including dentistry, ${ }^{10}$ cancer, ${ }^{6}$ pharmacology, ${ }^{11}$ radiology, ${ }^{12}$ mental disorders ${ }^{13}$ or on scholarly literature and life sciences topics. ${ }^{14-18}$ Previous studies show an increasing trend in the number of retraction publications in journals indexed on the Science Citation Index Expanded, as well as in the Medline database between 1990 and $2009 .{ }^{4}$ The main concern about increasing number of retraction publications in biomedical research is that unreliable information can put patients at

Copyright (C) 2021 The Author(s). This is an open-access article distributed under the terms of the Creative Commons Attribution License (http:// creativecommons.org/licenses/by/4.0), which permits unrestricted use, distribution, and reproduction in any medium, provided the original work is properly cited. 
risk. ${ }^{19}$ Since the field of medical sciences deals with human health, this issue may have significant dimensions and consequences. ${ }^{11}$ In addition, evidence suggests that many of the retraction medical articles have been cited. ${ }^{19}$ This indicates that not only are patients included in retraction studies at risk but also studies that cite these articles may present risks to patients.

\section{Objectives}

In the last decade, Iran's scientific articles have grown significantly and according to the statistics published from the Scopus database in 2012, it was ranked 17 th in the world. ${ }^{20,21}$ However, scientific misconduct has also grown. ${ }^{22}$ As mentioned, the retraction of articles is mostly due to intentional errors that means scientific misconduct, thus reviewing the retracted articles can help both researchers and scientific research policy makers in the country to find appropriate solutions to solve this problem. The increasing rate of retracted publications in the scientific literature is an important emerging phenomenon of which clinicians and researchers should be aware. Considering the importance of reviewing retracted publications, we conducted this descriptive observational study to identify the frequency of retracted Iranian publications, compared to those of other countries and adjust them with influential parameters such as research growth and growth of retracted publications worldwide.

\section{Methods}

\subsection{Database Sources}

For the present study, the statistics of publication history were extracted from Scopus ${ }^{\circledast}$ database. Since there are a lot of database indexes (including the overlaps of publication), we selected Scopus as one of the largest index abstract and citation databases of peer-reviewed literature to extract the number of published papers annually for each country and region under study. Additionally, we used the SCImago Journal and Country Rank (http://www.scimagojr.com) as a portal that includes the journals and countries' scientific indicators developed from the information contained in the Scopus ${ }^{\circledast}$ database. On the other hand, we used Retraction Watch database (http://retractionwatch.com) to extract the absolute number of retractions for the corresponding countries and regions under study. Retraction Watch database is a blog that reports on the retractions of scientific papers and related topics.

\subsection{Period Under Study}

All statistics belonged to the years 2008 - 2017, however, we broke up a decade to two departed five-year periods were defined to make the growth for both publication and retraction, first the period of 2008-2012 and second the period of 2013-2017. The first date is assumed as the baseline to calculate the scientific growth which happened in the next date (including a five-year periodical time for each).

\subsection{Science-Metric Indexes}

Retraction growth: To calculate the growth of retraction for each proposed country (or region), first the rate of an absolute number of retracted papers over the years 20132017 was divided into similar number for the years 20082012 , then this rate was adjusted to the retracted rate which similarly computed for the total retracted statistics of the world.

Retraction growth per 10,000 publication: This index was calculated from the absolute number of retracted papers for both periodical times (2008-2012 and 20132017), adjusted to 10,000 published papers for the same date (from Scopus ${ }^{\circledR}$ database).

Publication growth and adjusted publication growth (world): Similar to the retraction growth, first we calculated the rate of publication increasing (according to the statistics extracted from Scopus ${ }^{\circledR}$ database) for these mentioned period time (2008-2012 and 2013-2017), then based on the same method, we adjusted the same rate of publication for the total world, which means the rate of increase in the number of articles (or abstract) indexed in Scopus ${ }^{\circ}$ database to previous five-year (2013-2017), compared to the other periodical five-year (2008-2012), adjusted to the world's publication rate (publication growth adjusted to world's publication growth).

Retraction growth was adjusted to publication growth: The index was calculated by dividing the retraction growth into corresponding publication growth, for each proposed country (or region).

Regional Comparison of Retraction: To compare the number of Iranian retraction papers with that of other regions in the world, a Poisson Regression Model was used adjusted to the number of published documents, growth domestic production (GDP), income (high, low and middle, low, lower-middle, middle, and upper middle income according to the world bank categorization) and $\mathrm{H}$ index (according to the http://www.scimagojr.com) during the period under study.

\section{Results}

After searching in Scopus ${ }^{\circledast}$ database and Retraction Watch database, 15,802 retracted publications were identified worldwide from 2008 to 2017 . However, we have seen a decrease in the number of retracted articles in the world between the years 2013 and 2017 compared to the period from 2008 to 2012 , so that 11,238 articles from 2008 to 2012 and 4546 ones from 2013 to 2017 were retracted all over the world. The highest number of retracted publications were observed in Asia region (10,942), followed by Western Europe (2943), Northern America (2,157), Middle East (1012), Eastern Europe (385), Pacific (235), Latin America (225) and finally in Africa (211) between 2008 and 2017. Within these regions, Asiatic region, Latin America, Northern America, and Western Europe, the number of retracted articles decreased from 2013 to 2017 compared with 2008 to 2012, while in other regions the numbers of retracted publications had increased during the second 
5 -year period. The highest growth of retracted articles (1.24) in the second 5-year (2013-2017) compared to the first 5-year (2008-2012) period of study belonged to the Middle East region.

The statistics of retraction growth, adjusted retraction growth (for publication growth), and adjusted publication growth (for the world's publication growth) from 2013 to 2017 compared to 2008-2012 are presented in Table 1. Also, Figures 1 and 2 show the indicators shown in Table 1 . The results show the status of retracted Iranian publications among other countries and the region. According to the results, the retraction growth of Iran (for the second period under study, compared to the first one) was higher than some western and developed countries, but less than some developing countries, including Turkey, Egypt, Mexico, Saudi Arabia, etc. The retraction growth adjusted to publication index showed less than $1 \%(0.82)$ of all scientific articles published by Iranian researcher have been retracted. Although in countries such as Turkey (1.04), Ukraine (1.09), Russia (1.11), South Africa (1.18), Poland (1.73), Nigeria (1.73), and Colombia (2.69), the retracted rate of articles was higher than $1 \%$ compared to a scientific publication produced in those countries, but this index (retraction growth adjusted for publication growth) for most countries, such as Iran, has been less than $1 \%$. In addition, the rate of retraction of scientific articles in Iran

Table 1. Statistics of Retraction Growth, Adjusted Retraction Growth (for Publication Growth), and Adjusted Publication Growth (for World's Publication Growth) for Different Countries Including Iran

\begin{tabular}{|c|c|c|c|c|c|}
\hline Country (or Region)* & $\begin{array}{c}\text { Retraction Growth } \\
\text { Number of Retracted Papers } \\
(2013-2017 / 2008-2012)\end{array}$ & $\begin{array}{l}\text { Retraction Growth Per } \\
10,000 \text { Publication }\end{array}$ & $\begin{array}{c}\text { Retraction Growth } \\
\text { Adjusted to Publication } \\
\text { Growth }\end{array}$ & $\begin{array}{l}\text { Retraction Growth } \\
\text { Adjusted to World's } \\
\text { Retraction Growth }\end{array}$ & $\begin{array}{l}\text { Publication Growth } \\
\text { Adjusted to World's } \\
\text { Publication Growth }\end{array}$ \\
\hline China & $0.18(1348 / 7503)$ & 0.0011 & 0.13 & 0.44 & 1.19 \\
\hline Asiatic Region & $0.26(2238 / 8704)$ & 0.0008 & 0.19 & 0.64 & 1.14 \\
\hline Taiwan & $0.28(56 / 200)$ & 0.0172 & 0.28 & 0.69 & 0.84 \\
\hline United Arab Emirates & $0.6(3 / 5)$ & 0.4068 & 0.31 & 1.48 & 1.66 \\
\hline Czech Republic & $0.48(12 / 25)$ & 0.0587 & 0.34 & 1.19 & 1.19 \\
\hline Brazil & $0.65(51 / 78)$ & 0.0264 & 0.47 & 1.62 & 1.17 \\
\hline Saudi Arabia & $1.33(57 / 43)$ & 0.2472 & 0.50 & 3.28 & 2.24 \\
\hline Japan & $0.52(139 / 269)$ & 0.0098 & 0.51 & 1.28 & 0.86 \\
\hline Romania & $0.76(50 / 66)$ & 0.1376 & 0.57 & 1.87 & 1.12 \\
\hline South Korea & $0.76(164 / 215)$ & 0.0267 & 0.58 & 1.89 & 1.12 \\
\hline Morocco & $1.14(8 / 7)$ & 0.7109 & 0.58 & 2.83 & 1.67 \\
\hline Germany & $0.69(156 / 226)$ & 0.0105 & 0.59 & 1.71 & 0.98 \\
\hline New Zealand & $0.8(8 / 10)$ & 0.1402 & 0.65 & 1.98 & 1.05 \\
\hline Latin America & $0.89(106 / 119)$ & 0.0183 & 0.65 & 2.20 & 1.16 \\
\hline India & $1.09(384 / 351)$ & 0.0243 & 0.66 & 2.70 & 1.41 \\
\hline Egypt & $1.33(57 / 43)$ & 0.2071 & 0.66 & 2.79 & 1.46 \\
\hline Tunisia & $1.06(18 / 17)$ & 0.4285 & 0.69 & 2.62 & 1.3 \\
\hline Spain & $0.86(89 / 103)$ & 0.0259 & 0.69 & 2.14 & 1.05 \\
\hline United States & $0.77(870 / 1127)$ & 0.003 & 0.69 & 1.91 & 0.94 \\
\hline Northern America & $0.79(950 / 1207)$ & 0.0027 & 0.71 & 1.95 & 0.94 \\
\hline United Kingdom & $0.87(202 / 231)$ & 0.0115 & 0.75 & 2.16 & 0.98 \\
\hline Western Europe & $0.88(901 / 1021)$ & 0.0028 & 0.76 & 2.18 & 0.98 \\
\hline Mexico & $1(13 / 13)$ & 0.1068 & 0.76 & 2.47 & 1.11 \\
\hline Canada & $0.95(104 / 109)$ & 0.024 & 0.82 & 2.36 & 0.98 \\
\hline Iran & $1.27(305 / 240)$ & 0.0791 & 0.82 & 3.14 & 1.31 \\
\hline Middle East & $1.24(561 / 451)$ & 0.0221 & 0.83 & 3.08 & 1.26 \\
\hline Eastern Europe & $1.15(206 / 179)$ & 0.0149 & 0.83 & 2.84 & 1.17 \\
\hline Africa & $1.34(121 / 90)$ & 0.0658 & 0.85 & 3.32 & 1.34 \\
\hline Italy & $1.09(177 / 163)$ & 0.027 & 0.86 & 2.68 & 1.08 \\
\hline Chile & $1.43(10 / 7)$ & 0.3642 & 0.90 & 3.53 & 1.35 \\
\hline Algeria & $1.64(23 / 14)$ & 0.8616 & 0.91 & 4.06 & 1.52 \\
\hline France & $1.06(110 / 104)$ & 0.0228 & 0.93 & 2.61 & 0.96 \\
\hline Australia & $1.31(124 / 95)$ & 0.039 & 0.96 & 3.23 & 1.16 \\
\hline Argentina & $1.2(12 / 10)$ & 0.2436 & 0.96 & 2.97 & 1.06 \\
\hline Turkey & $1.39(89 / 64)$ & 0.0904 & 1.04 & 3.44 & 1.13 \\
\hline Ukraine & $1.5(3 / 2)$ & 0.3924 & 1.09 & 3.71 & 1.16 \\
\hline Russian Federation & $1.87(28 / 15)$ & 0.0837 & 1.11 & 4.61 & 1.43 \\
\hline South Africa & $1.89(36 / 19)$ & 0.2738 & 1.18 & 4.68 & 1.36 \\
\hline Pacific Region & $1.28(132 / 103)$ & 0.0333 & 1.73 & 3.17 & 0.63 \\
\hline Poland & $2.39(48 / 18)$ & 0.1562 & 1.73 & 5.91 & 1.17 \\
\hline Colombia & $5(10 / 2)$ & 1.689 & 2.69 & 12.36 & 1.57 \\
\hline
\end{tabular}

*The statistics were sorted according to Retract Growth Adjusted for Publication Growth 


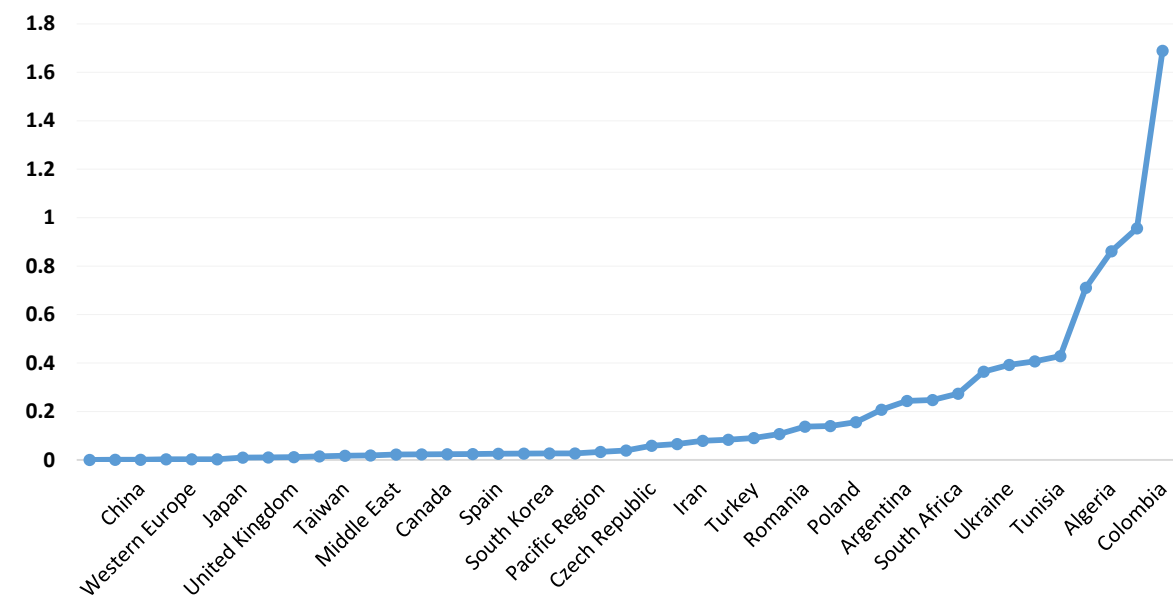

Figure 1. Retraction Growth Per 10,000 Publication (2017-2013 Compared to 2012-2008).

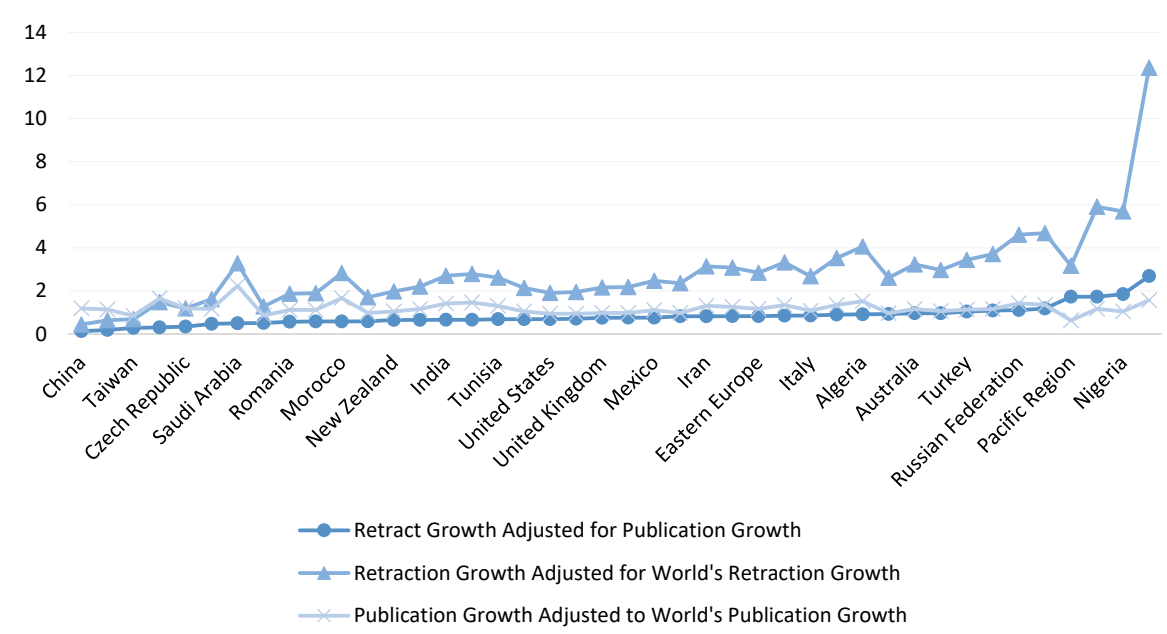

Figure 2. Adjusted Retraction Growth and Publication Growth (2017-2013 Compared to 2012-2008).

compared to this rate in the world was (3.14). China with the lowest rate (0.44) and Colombia with the highest rate (12.36) had the rate of retracted articles adjusted to world's retraction growth.

The Poisson regression analysis showed that the number of retracted documents for Iranian scientists was significantly higher than those of other regions (adjusted for the number of published documents, GDP, income, and $\mathrm{H}$ index during the period under study), except for Western Europe whose result indicated the same pattern. The results of Poisson regression model are presented in Table 2. The results indicated the number of retracted scientific publications of Africa (OR: 0.09, 95\% CI: 0.07$0.11, P<0.001$ ), Asiatic Region (OR: 0.87, 95\% CI: $0.77-$ 0.99, $P=0.03$ ), Eastern Europe (OR: 0.11, 95\% CI: 0.09$0.13, P<0.001$ ), Latin America (OR: 0.14, 95\% CI: 0.11$0.16, P<0.001$ ), Middle East (OR: 0.21, 95\% CI: 0.18-0.24, $P<0.001$ ), Northern America (OR: 0.13, 95\% CI: 0.09-0.17, $P<0.001$ ) and Pacific Region (OR: 0.45, 95\% CI: 0.37-0.54, $P<0.001)$ were significantly lower than retracted Iranian publications.

\section{Discussion}

The annual number of Iranian publications in the scientific literature is increasing rapidly, and consequently, the number of retracted publications has increased. To date, four studies have been conducted in the field of retraction Iranian publications. Two studies on retracted Iranian publications have been published in the Web of Science database, ${ }^{23,24}$ and two other studies on retracted Iranian publications in the PubMed database. ${ }^{25,26}$ The most important aspects of the current study, compared to the

Table 2. The Comparison of Regional Retraction With Iran's Retraction, From 2008-2017

\begin{tabular}{lccc}
\hline Country (or Region) & OR $^{*}$ & $\boldsymbol{P}$ value & $\mathbf{9 5} \% \mathbf{C l}$ \\
\hline Africa & 0.09 & $<0.001$ & $0.07-0.11$ \\
Asiatic Region & 0.87 & 0.03 & $0.77-0.99$ \\
Eastern Europe & 0.11 & $<0.001$ & $0.09-0.13$ \\
Latin America & 0.14 & $<0.001$ & $0.11-0.16$ \\
Middle East** & 0.21 & $<0.001$ & $0.18-0.24$ \\
Northern America & 0.13 & $<0.001$ & $0.09-0.17$ \\
Pacific Region & 0.45 & $<0.001$ & $0.37-0.54$ \\
Western Europe & 0.99 & 0.92 & $0.82-1.19$ \\
Africa & 0.09 & $<0.001$ & $0.07-0.11$ \\
\hline
\end{tabular}

*Adjusted to the number of published documents, GDP, income, and $\mathrm{H}$ index during the period under study; **Iran was excluded 
four studies studying the retracted publications of Iran, is that in addition to identify the frequency of retracted Iranian publications and compare them with other countries, we adjusted the rate of retracted publications with influential parameters such as research growth and growth of retracted publications worldwide.

According to the results of the current study, less than $1 \%(0.82)$ of all scientific articles published by Iranian researchers were retracted. However, the rate of retracted scientific articles in Iran compared to the rate in the world and many other countries and regions was significantly higher. Although there is a substantial increase in the rate of retracted Iranian published papers during the study period in almost one decade, the adjusted rate of this growth was at a moderate rate, compared to other regions and countries. This growth was less than the same developing countries in Middle East and a bit higher than developed countries in the West. Meanwhile, according to adjusted Poisson regression model, the pattern of this retraction is almost similar to that of Western Europe.

A descriptive cross-sectional study conducted by Masoomi and Amanollahi ${ }^{25}$ identified 145 retracted Iranian articles on PubMed database and over $80 \%$ of articles were retracted due to scientific misconduct and duplicate publication (19.31\%). A the result of a study by Moradi and Janavi ${ }^{23}$ showed that the retraction rate has increased from the year 2008, but there was no significant correlation between this rate and publication rate the highest type of scientific misconduct is introduced as plagiarism. A study by Mansourzadeh et $\mathrm{al}^{26}$ to retrieve all retracted Iranian publications in PubMed database revealed 164 retracted Iranian publications. "Islamic Azad University" and "Tehran University of Medical Sciences (TUMS)" were two affiliations that have received the highest number of retracted publications. The most issuer of retraction publications was editor-in-chief and the most mentioned reasons for retractions were authorship issues, plagiarism, and redundant publication. In addition, a study by Moradi et $\mathrm{al}^{24}$ suggests that the retracted articles have been on rise in recent years. Overall, Iran, India, and Pakistan had the highest rates of scientific misconduct.

Although Iranian retracted publications represent a small fraction of all Iranian publications, even one retracted publication is a lot and is considered to be unethical behavior. Therefore authors should be more aware of the consequences of misbehavior in scientific publications. ${ }^{27}$ The editor-in-chief for Journals should follow the instructions set out in the Committee on Publication Ethics (COPE) guidelines, ${ }^{28}$ and new technologies for plagiarism detection should be used. ${ }^{29,30}$ Moreover, implementing monitoring of pre-publication processes can certainly be useful that consequently reduces the scientific misconducts.

\section{Conclusion}

Although retracted Iranian publications make up a small percentage of all Iranian publications, the number of
Research Highlights

What Is Already Known?

- Retraction of articles occurs as a result of scientific misconducts or honest errors.

- $\quad$ Retracted Iranian publications are on the rise.

\section{What Does This Study Add?}

- Overall, 545 Iranian retracted publications from 2008 to 2017 were identified from Scopus ${ }^{\circledR}$ database and Retraction Watch database.

- The results showed that less than $1 \%(0.82)$ of all scientific articles published by Iranian researchers were retracted.

- The rate of retracted scientific articles in Iran compared to the rate in the world was significantly higher in many other countries and regions.

- We suggest; authors should be more aware of the consequences of misbehavior in scientific publications. The editor-in-chief for Journals should follow the instructions set out in the COPE guidelines, and new technologies for plagiarism detection should be used. Moreover, implementing monitoring of pre-publication processes can certainly be useful.

retracted publications is increasing. It is important to recognize the reasons for scientific misconducts and to provide researchers with proper education. By encouraging researchers to engage in writing and study ethics training while penalizing those who misconduct, these actions can be avoided.

\section{Authors' Contributions}

MAP, MKF, and AVA developed the study concept. All authors contributed to the study design. Testing and data collection were performed by FRB and AVA, and MAP. Data analysis and interpretation were performed by FRB and MAP. All authors approved the final version of the manuscript for submission.

\section{Conflict of Interest Disclosures}

The authors declared that they have no conflict of interest.

\section{Ethical Approval}

This study was approved by Baqiyatallah University of Medical Sciences Ethics Committee, Tehran, Iran.

\section{Acknowledgments}

The authors express their gratitude for guidance and advice from the "Clinical Research Development Unit of Baqiyatallah Hospital”.

\section{References}

1. Wager $\mathrm{E}$, Williams $\mathrm{P}$. Why and how do journals retract articles? an analysis of Medline retractions 1988-2008. J Med Ethics. 2011;37(9):567-570. doi:10.1136/jme.2010.040964

2. Kleinert S. COPE's retraction guidelines. Lancet. 2009;374(9705):1876-1877. doi:10.1016/s01406736(09)62074-2 
3. Decullier $E$, Huot $L$, Maisonneuve $H$. What time-lag for a retraction search on PubMed? BMC Res Notes. 2014;7:395. doi:10.1186/1756-0500-7-395.

4. Decullier E, Huot L, Samson G, Maisonneuve H. Visibility of retractions: a cross-sectional one-year study. BMC Res Notes. 2013;6:238. doi:10.1186/1756-0500-6-238.

5. Chen C, Hu Z, Milbank J, Schultz T. A visual analytic study of retracted articles in scientific literature. J Am Soc Inf Sci Technol. 2013;64(2):234-253. doi:10.1002/asi.22755.

6. Bozzo A, Bali K, Evaniew N, Ghert M. Retractions in cancer research: a systematic survey. Res Integr Peer Rev. 2017;2:5. doi:10.1186/s41073-017-0031-1.

7. Fang FC, Steen RG, Casadevall A. Misconduct accounts for the majority of retracted scientific publications. Proc Natl Acad Sci U S A. 2012;109(42):17028-17033. doi:10.1073/ pnas. 1212247109.

8. Stretton S, Bramich NJ, Keys JR, et al. Publication misconduct and plagiarism retractions: a systematic, retrospective study. Curr Med Res Opin. 2012;28(10):1575-1583. doi:10.1185/03 007995.2012.728131.

9. Almeida RM, de Albuquerque Rocha K, Catelani F, FontesPereira AJ, Vasconcelos SM. Plagiarism allegations account for most retractions in major Latin American/Caribbean databases. Sci Eng Ethics. 2016;22(5):1447-1456. doi:10.1007/s11948015-9714-5.

10. Nogueira TE, Gonçalves AS, Leles CR, Batista AC, Costa LR. A survey of retracted articles in dentistry. BMC Res Notes. 2017;10(1):253. doi:10.1186/s13104-017-2576-y.

11. Samp JC, Schumock GT, Pickard AS. Retracted publications in the drug literature. Pharmacotherapy. 2012;32(7):586-595. doi:10.1002/j.1875-9114.2012.01100.x.

12. Rosenkrantz AB. Retracted publications within radiology journals. AJR Am J Roentgenol. 2016;206(2):231-235. doi:10.2214/ajr.15.15163.

13. Balhara YP, Mishra A. A study exploring attributes and nature of the retracted literature on mental disorders. Indian J Med Ethics. 2015;12(1):30-37. doi:10.20529/ijme.2015.007.

14. Budd JM, Sievert M, Schultz TR. Phenomena of retraction: reasons for retraction and citations to the publications. JAMA. 1998;280(3):296-297. doi:10.1001/jama.280.3.296.

15. Damineni RS, Sardiwal KK, Waghle SR, Dakshyani MB. A comprehensive comparative analysis of articles retracted in 2012 and 2013 from the scholarly literature. J Int Soc Prev Community Dent. 2015;5(1):19-23. doi:10.4103/22310762.151968 .

16. Singh HP, Mahendra A, Yadav B, Singh H, Arora N, Arora M. A comprehensive analysis of articles retracted between 2004 and 2013 from biomedical literature - a call for reforms. J Tradit Complement Med. 2014;4(3):136-139. doi:10.4103/22254110.136264

17. Foo JY. A retrospective analysis of the trend of retracted publications in the field of biomedical and life sciences. Sci Eng Ethics. 2011;17(3):459-468. doi:10.1007/s11948-0109212-8.

18. Grieneisen ML, Zhang M. A comprehensive survey of retracted articles from the scholarly literature. PLoS One. 2012;7(10):e44118. doi:10.1371/journal.pone.0044118.

19. Steen RG. Retractions in the medical literature: how many patients are put at risk by flawed research? J Med Ethics. 2011;37(11):688-692. doi:10.1136/jme.2011.043133.

20. Akhondzadeh S. Iranian science shows world's fastest growth: ranks 17th in science production in 2012. Avicenna J Med Biotechnol. 2013;5(3):139.

21. Kharabaf $S$, Abdollahi M. Science growth in Iran over the past 35 years. J Res Med Sci. 2012;17(3):275-279.

22. Sadeghi-Bazargani H, Nikniaz L, Yousefi Nodeh HR. Street research market: dealing with scientific misconduct in Iran. BMC Med Ethics. 2020;21(1):78. doi:10.1186/s12910-02000518-x.

23. Moradi S, Janavi E. A scientometrics study of Iranian retracted papers. Iran J Inf Process Manag. 2018;33(4):1789-1808. [Persian].

24. Moradi S, Janavi E, Kazemi H. A comparative study of scientific misconduct through the world. National Studies on Librarianship and Information Organization. 2018;28(4):7594. [Persian].

25. Masoomi R, Amanollahi A. Why Iranian biomedical articles are retracted? J Med Educ Dev. 2018;13(2):87-100. [Persian].

26. Mansourzadeh MJ, Ghazimirsaeid J, Motamedi N, Najafi A, Abdullahi Abubakar A, Dehdarirad H. A survey of Iranian retracted publications indexed in PubMed. Iran J Public Health. 2021;50(1):188-194. doi:10.18502/ijph.v50i1.5086.

27. de Vries R, Anderson MS, Martinson BC. Normal misbehavior: scientists talk about the ethics of research. J Empir Res Hum Res Ethics. 2006;1(1):43-50. doi:10.1525/jer.2006.1.1.43.

28. Patel J. New COPE guidelines on publication process manipulation: why they matter. Res Integr Peer Rev. 2018;3:13. doi:10.1186/s41073-018-0059-x.

29. Bazdaric K. Plagiarism detection--quality management tool for all scientific journals. Croat Med J. 2012;53(1):1-3. doi:10.3325/cmj.2012.53.1.

30. Masic I, Begic E, Dobraca A. Plagiarism detection by online solutions. Stud Health Technol Inform. 2017;238:227-230. 